\title{
Pure-Nickel-Coated Multiwalled Carbon Nanotubes Prepared by Electroless Deposition
}

\author{
Susumu Arai, ${ }^{\mathrm{a}, *, \mathrm{z}}$ Mitsuhiro Kobayashi, ${ }^{\mathrm{a}}$ Tohru Yamamoto, ${ }^{\mathrm{a}}$ and Morinobu Endo ${ }^{\mathrm{b}}$ \\ ${ }^{a}$ Department of Chemistry and Material Engineering and ${ }^{b}$ Department of Electrical and Electronic \\ Engineering, Faculty of Engineering, Shinshu University, Nagano 380-8553, Japan
}

\begin{abstract}
Pure-nickel-coated multiwalled carbon nanotubes (MWCNTs) have been prepared by electroless deposition. Gluconic acid and hydrazine were respectively used as the complexing and reducing agents for nickel ions. The deposits were heat-treated. The microstructures and magnetic properties of the deposits were examined. The MWCNTs were homogeneously coated with pure nickel and their surfaces were relatively bumpy. These pure-nickel-coated MWCNTs exhibited ferromagnetism and had higher magnetizations and coercivities than electroless Ni-P alloy-coated MWCNTs. The bumpy morphology of the pure-nickel coating became relatively smooth on heat-treatment.
\end{abstract}

(C) 2010 The Electrochemical Society. [DOI: 10.1149/1.3489535] All rights reserved.

Manuscript submitted July 19, 2010; revised manuscript received August 25, 2010. Published September 16, 2010.

Carbon nanotubes $(\mathrm{CNTs})^{1,2}$ exhibit excellent mechanical characteristics in addition to having high thermal and electrical conductivities. Practical applications of CNTs are being actively researched. Recently, metal coating of CNTs by electroless deposition has been investigated. Metal deposition or coating using cobalt, ${ }^{3}$ nickel, ${ }^{4-9}$ or their alloys ${ }^{10,11}$ can impart CNTs with magnetic properties and high wettabilities with composite matrices. Electroless nickel deposition on CNTs has mainly been studied. However, the electroless nickel deposits used were not pure nickel but Ni-P alloy deposits because phosphorus-containing compounds (e.g., sodium hypophosphite) were used as the reducing agent for nickel ions. Electroless $\mathrm{Ni}-\mathrm{P}$ alloys generally have inferior magnetic properties to pure nickel. Furthermore, if Ni-P alloy-coated CNTs are mixed with metal matrices, both nickel and phosphorus are incorporated in the resulting composites.

Therefore, electroless pure-nickel deposition on CNTs is considered to be very promising for extending the applications of CNTs. However, little research on electroless pure-nickel deposition on CNTs has been reported.

In this study, electroless deposition of pure nickel on CNTs was investigated and the magnetic properties of the pure-nickel-coated CNTs were studied.

\section{Experimental}

The CNTs used [vapor grown carbon fibers (VGCFs), Showa Denko Co. Ltd.] were commercially available multiwalled carbon nanotubes (MWCNTs), which were produced by catalyst-assisted chemical vapor deposition ${ }^{12}$ and heat-treated at $2800^{\circ} \mathrm{C}$ in $\mathrm{Ar}$ for 30 min. The VGCFs were typically $150 \mathrm{~nm}$ in diameter and $10 \mu \mathrm{m}$ long. To make the VGCFs hydrophilic, $0.2 \mathrm{~g} \mathrm{dm}^{-3}$ VGCFs were placed in a $2 \times 10^{-5} \mathrm{~mol} \mathrm{dm}^{-3}$ polyacrylic acid ${ }^{5}$ solution and subjected to stirring and ultrasonic agitation. The VGCFs were then filtered and rinsed. To adsorb $\mathrm{Sn}^{2+}$ ions on the VGCFs, they were then immersed in a $4.4 \times 10^{-2} \mathrm{~mol} \mathrm{dm}^{-3} \quad \mathrm{SnCl}_{2} \cdot 2 \mathrm{H}_{2} \mathrm{O}$ $+0.12 \mathrm{~mol} \mathrm{dm}^{-3} \mathrm{HCl}$ solution for $6 \mathrm{~min}$ at $25^{\circ} \mathrm{C}$ and were ultrasonically agitated. After filtration and rinsing, the VGCFs were immersed in a $5.6 \times 10^{-4} \mathrm{~mol} \mathrm{dm}^{-3} \mathrm{PdCl}_{2}+0.12 \mathrm{~mol} \mathrm{dm}^{-3} \mathrm{HCl}$ solution for $6 \mathrm{~min}$ at $25^{\circ} \mathrm{C}$ and were ultrasonically agitated to form palladium catalytic nuclei on the VGCFs. After filtration and rinsing, the VGCFs were placed in an electroless nickel plating bath. The composition of the electroless pure-nickel plating bath was $0.05 \mathrm{M} \mathrm{NiCl}_{2} \cdot 6 \mathrm{H}_{2} \mathrm{O}+0.5 \mathrm{M} \mathrm{C}_{6} \mathrm{H}_{12} \mathrm{O}_{7}+0.4 \mathrm{M} \mathrm{N}_{2} \mathrm{H}_{4} \cdot \mathrm{H}_{2} \mathrm{O}$ $+0.5 \mathrm{M} \mathrm{H}_{3} \mathrm{BO}_{3}$. The bath contained gluconic acid and hydrazine ${ }^{13,14}$ as the complexing and reducing agents for nickel ions, respectively. The $\mathrm{pH}$ was adjusted to 12 . Electroless plating was performed at $80^{\circ} \mathrm{C}$ with stirrer agitation for various reaction

\footnotetext{
Electrochemical Society Active Member

${ }^{\mathrm{z}}$ E-mail: araisun@shinshu-u.ac.jp
}

times. After filtration and rinsing, the electroless-deposited VGCFs were dried. The deposits were then heat-treated in a vacuum at $400^{\circ} \mathrm{C}$ for $60 \mathrm{~min}$ using an IR furnace (Ulvac-Riko, Inc., MILA3000). For comparison, low phosphorus content electroless Ni-P alloy-coated $\mathrm{VGCFs}^{5}$ were also prepared using an electroless plating bath containing citrate and hypophosphite as the complexing and reducing agents, respectively $\left(0.08 \mathrm{M} \mathrm{NiSO}{ }_{4} \cdot 6 \mathrm{H}_{2} \mathrm{O}\right.$ $+0.2 \mathrm{M} \mathrm{NaH}_{2} \mathrm{PO}_{2} \cdot \mathrm{H}_{2} \mathrm{O}+0.08 \mathrm{M} \mathrm{C}_{6} \mathrm{H}_{5} \mathrm{Na}_{3} \mathrm{O}_{7} ; \mathrm{pH}$ 9) with stirrer agitation at $35^{\circ} \mathrm{C}$ for $60 \mathrm{~min}$. The deposits were examined by a field-emission-scanning electron microscope (FESEM; JEOL, JSM7000F). A cross-sectional polisher (JEOL, SM-09010) was used to prepare the cross-sectional samples for FESEM observation. The phase structure of the deposits on the VGCFs was analyzed by an X-ray diffractometer (XRD; Shimadzu Seisakusho Co., XRD-6000). The phosphorus content in the Ni-P alloy coating was measured using an electron probe X-ray microanalyzer (EPMA, Shimadzu Seisakusho EPMA-1610). The magnetic properties of the deposits were evaluated at room temperature using a vibrating sample magnetometer (Tamagawa Seisakusho Co., TM-VSMSH-30-1). The XRD and magnetic property measurements were performed before heat-treatment.

\section{Results and Discussion}

Figure 1 shows the SEM images of the deposits growing on the VGCFs. After $10 \mathrm{~min}$, very small granular deposits were observed on the VGCFs (Fig. 1a). The deposits grew on the VGCFs with
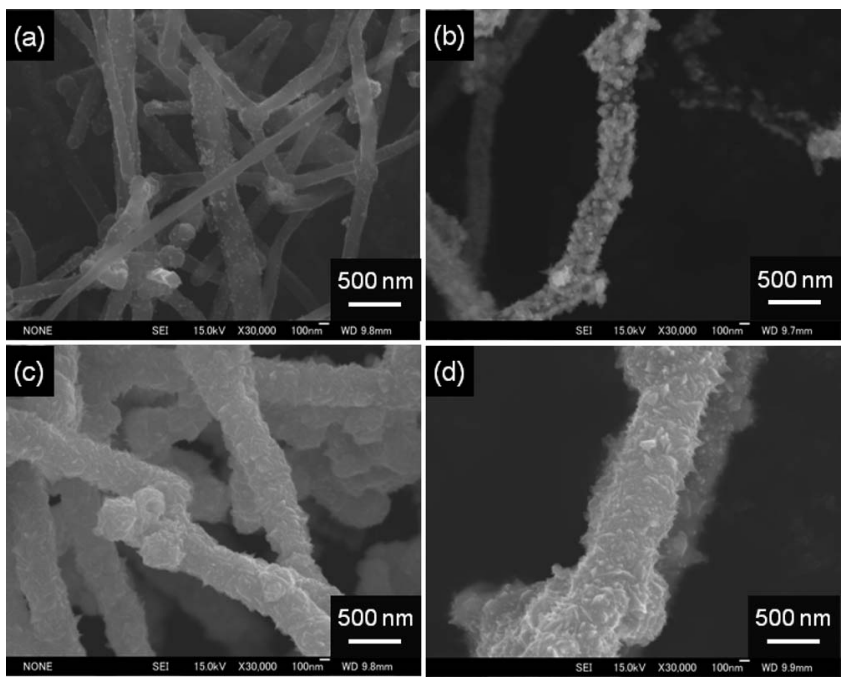

Figure 1. SEM images of the growth process of electroless deposits on the VGCFs after (a) 10, (b) 20, (c) 30, and (d) $60 \mathrm{~min}$. 

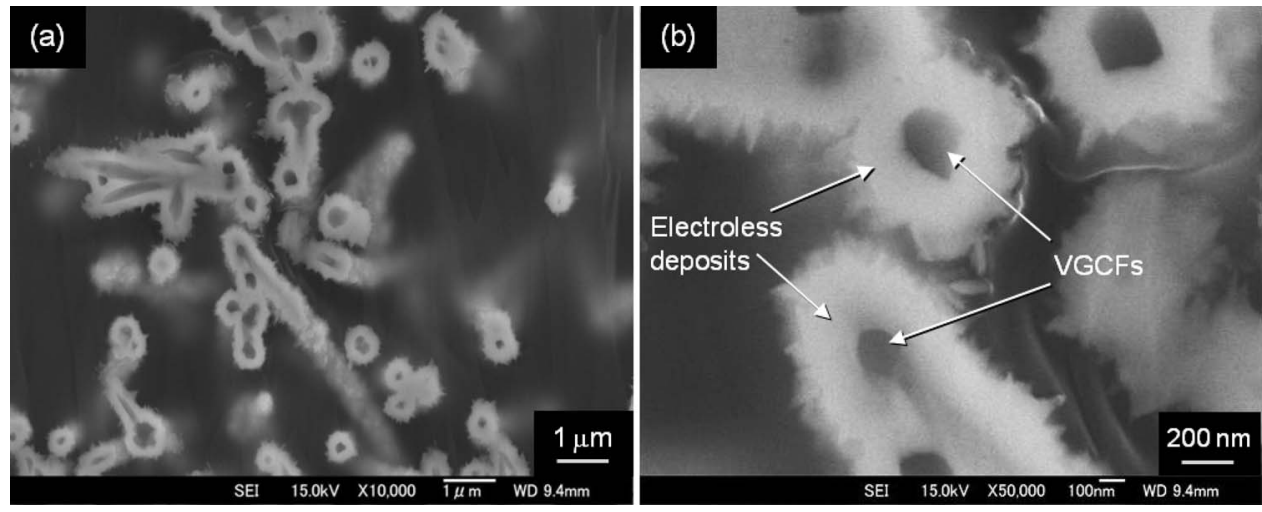

Figure 2. (a) Low and (b) high magnification cross-sectional SEM images of pure-nickel-coated VGCFs. Reaction time was $60 \mathrm{~min}$.

increasing reaction time. The VGCFs were completely coated with the deposits at a reaction time of $30 \mathrm{~min}$ (Fig. 1c and d). The deposits were $\sim 120$ and $200 \mathrm{~nm}$ thick after reaction times of 30 and $60 \mathrm{~min}$, respectively. Thus, the thickness of the deposits could be controlled by varying the reaction time.

Figure 2 shows the cross-sectional SEM images of coated VGCFs obtained using a reaction time of $60 \mathrm{~min}$. The VGCFs were completely coated with deposits and there were no gaps between the VGCFs and the deposits.

Figure 3 shows the XRD patterns of the deposits. All the diffraction peaks could be assigned to VGCFs (i.e., MWCNTs) and facecentered cubic nickel. The peaks assigned to nickel are sharp, indicating that the deposited nickel has a high crystallinity. The intensities of the nickel diffraction peaks increased with increasing

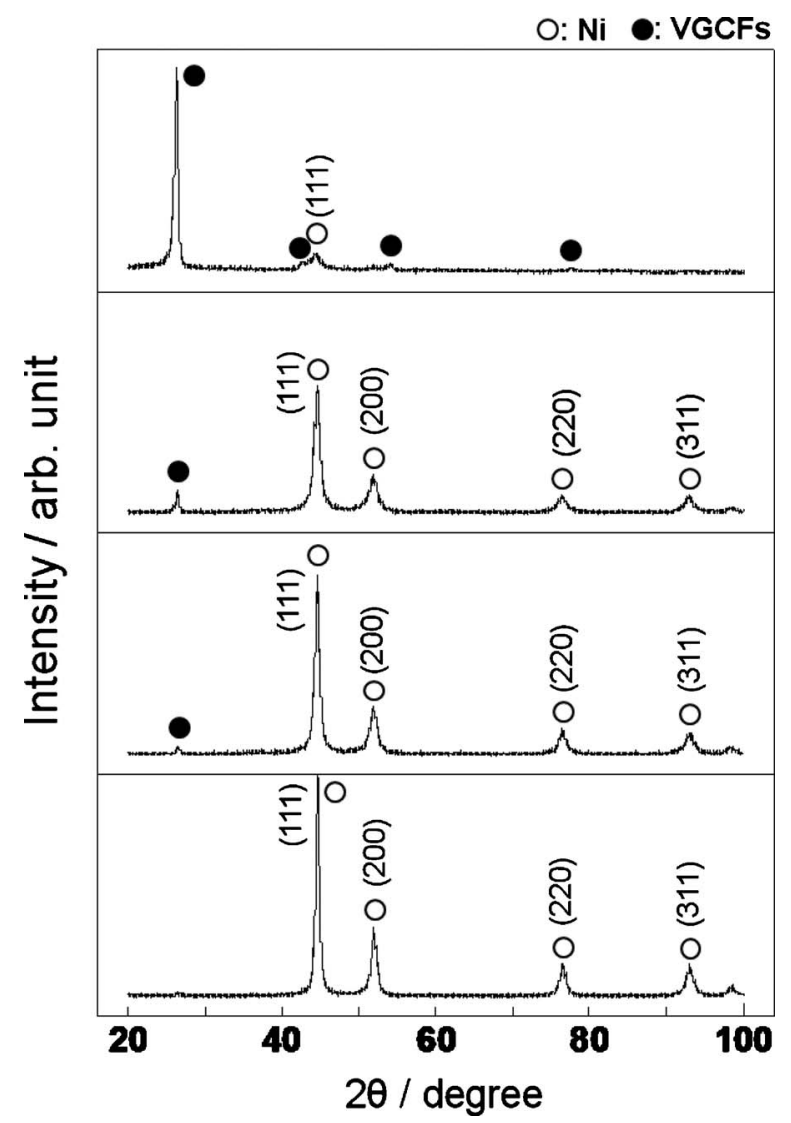

Figure 3. XRD patterns of electroless pure-nickel-coated VGCFs with reaction times of (a) 10, (b) 20, (c) 30, and (d) $60 \mathrm{~min}$. reaction time, whereas the intensities of the VGCF diffraction peaks decreased with increasing reaction time. Thus, the deposits on the VGCFs were confirmed to be pure nickel.

Figure 4 shows the magnetic hysteresis loops of the electroless pure-nickel-coated VGCFs. The films are $\sim 200$ nm thick. For comparison, it also shows the hysteresis loops of VGCFs and electroless Ni-P alloy-coated VGCFs. The Ni-P alloy coating has a low phosphorus content (about 2-3 mass \%) and is $\sim 200 \mathrm{~nm}$ thick. The VGCFs exhibited very little magnetization or coercivity. The purenickel-coated VGCFs showed obvious magnetization with a saturation magnetization $\left(M_{\mathrm{s}}\right)$ of $44 \mathrm{emu} \mathrm{g}^{-1}$. The pure-nickel-coated VGCFs had a coercivity $\left(H_{\mathrm{c}}\right)$ of $126 \mathrm{Oe}$. These magnetic properties are clearly higher than those of the Ni-P alloy film $\left(M_{\mathrm{s}}\right.$ 12 emu $\left.\mathrm{g}^{-1}, H_{\mathrm{c}}: 42 \mathrm{Oe}\right)$.

Figure $5 \mathrm{a}$ and $\mathrm{b}$ shows the SEM images of the pure-nickel-coated VGCFs before and after heat-treatment, respectively. Before heattreatment, the surface morphology of the pure-nickel coating is bumpy (Fig. 5a), whereas the surface morphology is relatively smooth after heat-treatment (Fig. 5b). This smoothing may be due to the recrystallization of the pure-nickel coatings.

\section{Conclusions}

Pure-nickel-coated MWCNTs were successfully fabricated by electroless deposition. The film thickness could be controlled by

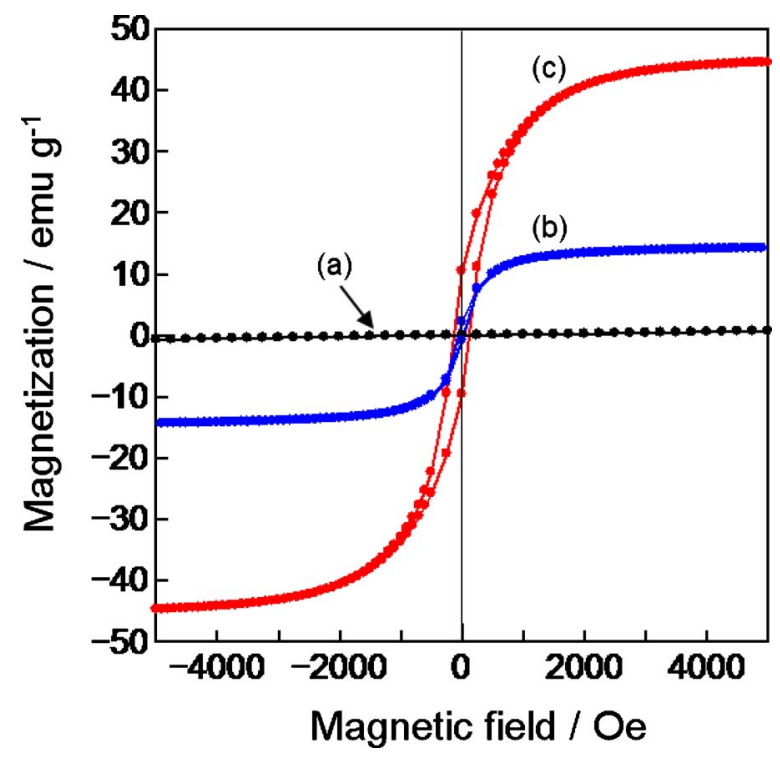

Figure 4. (Color online) Magnetic hysteresis loops of (a) VGCFs, (b) electroless Ni-P alloy-coated VGCFs, and (c) electroless pure-nickel-coated VGCFs. 

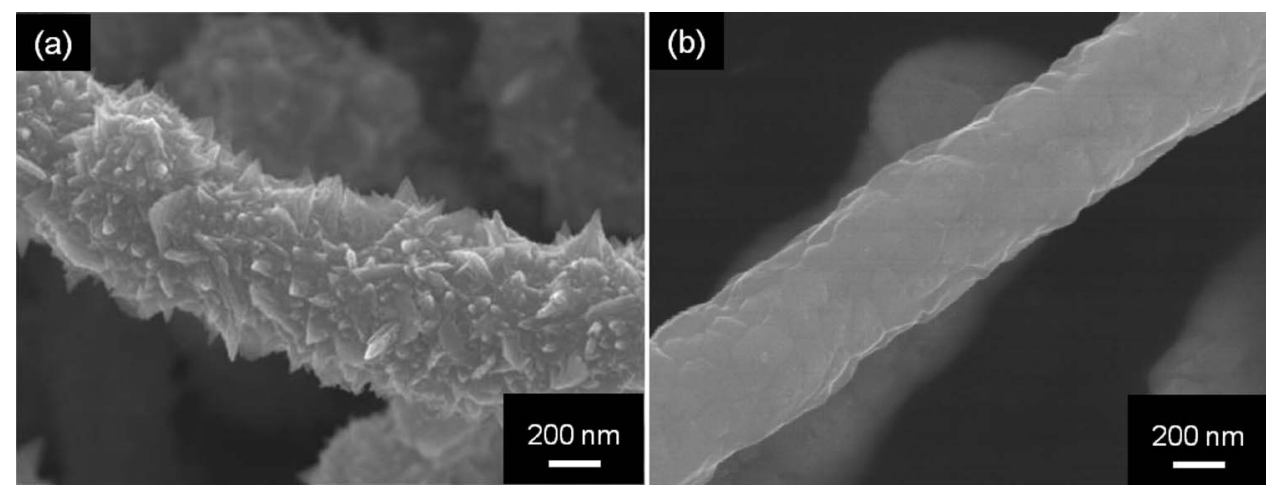

Figure 5. SEM images of pure-nickelcoated VGCFs (a) before and (b) after heat-treatment.

varying the reaction time. The pure-nickel-coated MWCNTs had higher saturated magnetizations and coercivities than the Ni-P alloycoated MWCNTs. Heat-treatment reduced the surface roughness of the pure-nickel coatings.

\section{Acknowledgments}

This research was supported by the Regional Innovation Cluster Program of Nagano, granted by MEXT, Japan.

Shinshu University assisted in meeting the publication costs of this ar-

\section{References}

1. A. Oberlin, M. Endo, and T. Koyama, J. Cryst. Growth, 32, 335 (1976).

2. S. Iijima and T. Ichihashi, Nature (London), 363, 603 (1993).
3. X. Chen, J. Xia, J. Peng, W. Li, and S. Xie, Compos. Sci. Technol., 60, 301 (2000) 4. J. Li, M. Moskovits, and T. L. Haslett, Chem. Mater, 10, 1963 (1998).

5. S. Arai and M. Endo, Electrochem. Commun., 6, 1029 (2004).

6. F. Wang, S. Arai, and M. Endo, Carbon, 43, 1716 (2005).

7. F. Wang, S. Arai, K. C. Park, K. Takeuchi, Y. J. Kim, and M. Endo, Carbon, 44, 1307 (2006).

8. X. Feng, G. Liao, J. Du, L. Dong, K. Jin, and X. Jian, Polym. Eng. Sci., 48, 1007 (2008).

9. T. Li, S. Qu, Z. Li, W. Tao, and M. Wang, Mater. Sci. Eng., A, 500, 182 (2009).

10. M. Ye, T. Xie, B. L. He, Y. C. Wu, G. W. Meng, L. D. Zhang, and J. Chin, Chem. Phys., 22, 411 (2009).

11. Y. Zhao, Y. J. Xue, H. Zheng, and Y. X. Duan, New Carbon Mater, 25, 65 (2010).

12. M. Endo, CHEMTECH, 18, 568 (1988).

13. P. Steinmetz, S. Alperine, A. F. Costantini, and P. Josso, Surf. Coat. Technol., 43-44, 500 (1990).

14. S. Haag, M. Burgard, and B. Ernst, Surf. Coat. Technol., 201, 2166 (2006). 